to operations as a relief for asthma, and the/servers, who have in general expressed them. possibility of sensitization to proteins should first be ruled out.

We feel that the following is a good and useful classification to use in determining the cause and treatment of bronchial asthma.

Ćlassification of Causes of Bronchial asthma. BRONCHIAL ASTHMA.

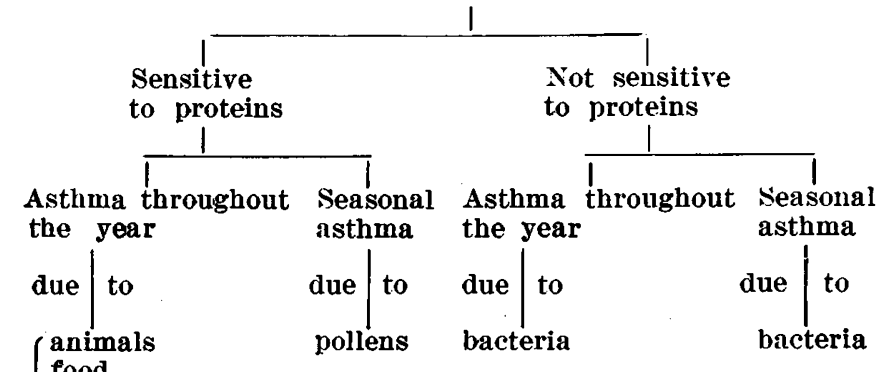

After what has been noted in this paper, the above classification needs no description. Although neurasthenic, neurotic and psychoneurotic conditions are frequently associated with bronchial asthma, we feel that these condi. tions are not sufficiently often a cause of asthma to warrant a place among causes of asthma. Furthermore, no provision is made for so-called cardiac and renal asthma, since we do not accept shortness of breath on exertion, nocturnal dyspnea and bronchitis, all of which are associated with cardiac and renal disease as bronchial asthma. The combination of all of these symptoms does in a way simulate bronchial asthma, but for such a syndrome we feel that the term asthmatic bronchitis is more appro. priate; such a term would imply bronchitis with asthmatic symptoms, and this is really the true condition present. Cardiac and renal patients may have true bronchial asthma; however, in these cases the asthmatic condition is entirely separate from the cardiac and renal disease; they are two distinct conditions not dependent upon each other.

\section{The Present Status of Immunization in HAX-FEVER.}

By J. L. Gmodale, M.D., Boston.

THE object of the following paper is to present briefly the results of an investigation begun in 1914, with the purpose of determining the value of desensitization in hay-fever.

Since the method was initiated by Noone and Freeman in 1911, the literature has become increasingly filled with reports from various ob- selves favorably as to the results obtained.

In an experience covering four years the writer has come to the conclusion that the majority of the reports hitherto published have not taken sufficiently into account the variability of the seasons in regard to the abundance of pollen produced, as well also as individual and temporary alterations in the physical state of the patients. It has seemed to me, therefore, preferable in the present communication to present a study of a relatively small number of patients, where the treatment has been carried out for not less than two years, in order to eliminate so far as possible such modifying factors.

In the examination of a given case of hayfever, the first point to determine is whether the vasomotor symptoms are actually excited by the pollen of plants, or whether they arise in response to a stimulation of the nasal nerves through other agencies. A fairly large proportion of the cases which have come under my observation have shown no response to any of the pollens tested, but have been excited by the fragrance of certain plants, such as lilies of the valley, sweet peas, hyacinths, lilacs, etc. In these plants the amount of pollen disseminated must be extremely slight, owing to the relatively small amount produced in the flower, and by the heavy and viscid character of the pollen grains themselves. Tests, moreover, with the pollen in such cases has failed to show a skin reaction, although the patient within the radius of the fragrance of the flower will be thrown into more or less violent attacks of sneezing or even of asthma. Such conditions I have termed in a previous paper olfactory vasomotor rhinitis or pseudo-hay. fever. It is therefore of great importance to test all cases on the skin even though their symptoms may be distinctly seasonal. I have, however, noted, that these olfactory types of vasomotor rhinitis display their symptoms usually during the earlier summer months. In most instances patients whose symptoms develop only in late August and early September, have been of the true anaphylactic type due to ragweed.

\section{SEASONAL VARIATIONS IN HAY-FEVER.}

A word should be said in regard to the variations which hay-fever cases show in the intensity of their symptoms from year to year. 
Aside from individual changes in health or in- A case of spring hay-fever will therefore find trinsic resistance, hay-fever symptoms may be immunity in the South or in California, but considered directly dependent upon the amount naturally such a change of climate at this seaof pollen which is received by the individual son may present obstacles. These spring cases upon the mucous membranes. A person living may therefore usually be advised to have imin the city receives naturally a smaller quan- munizing treatment. In the case of ragweed tity than one whose work and recreation bring hay-fever, the time of its occurrence coincides him more directly into the country. Aside with the vacation period of many persons, and from this factor, the character of the season the prescription of a change to the mountains should be noted. Hay-fever producing plants, or maritime provinces contains much that is if trees or well-established shrubs, are less agreeable. I have advised those persons, likely to exhibit variations from year to year, whose circumstances permit, to go into localiwhereas both grasses and ragweed will exhibit ties free from ragweed, rather than to undermarked variations dependent upon the season. take the treatment.

We should remember in respect to grasses, that these are essentially plants preferring cool, moist weather, and that the amount of pollen produced will be greater under these conditions, than where the season is hot and dry. The ragweed, on the other hand, is the most Northern representative of a Southern group of plants, and is especially dependent upon heat for its proper maturity. This explains its absence in Bethlehem, N. H., and similar localities, where the seasons are too short to enable it to ripen its seeds. The time of occurrence of ragweed hay-fever depends in great measure upon the earliness of the spring, and abservations carried on for a period of five years have shown, with a normal May temperature of 58 , the time of flowering ragweed in my locality is August 25th. If the May temperature is distinctly below the average the time of flowering is retarded, and is not even sufficiently accelerated by a hot July and August.

When a patient presents himself for the the treatment of hay-fever, it should be first determined whether in the individual case desensitizing treatment should be recommended, or whether the patient should be advised to seek refuge from his symptoms by a change of climate. In regard to the early forms of hayfever, namely from the trees and grasses, it should be recogized that the so-called hayfever resorts will not afford relief, since these in have reference only to the freedom of the locality from ragweed. A patient who wishes, therefore, to escape the early forms should direct his face to the South or far West, where the conditions are such as not to favor the development of grasses, or where the particular trees either are absent or have finished flowering. pollen for all of the compositae. 
COLLECTION AND PRESERVATION OF POLLEN.

One may in this vicinity feel reasonably confident that he can treat the cases which present themselves if he has pollen of the following plants: willow, poplar, maple, birch, oak, grass, rose and ragweed. Although frequently accused by patients of producing hayfever symptoms, horse chestnut, lilac, honeysuckle and peonies have not produced skin reactions. The pollen is best kept dry and will preserve its activity for many years, although after being once thoroughly desiccated, it requires soaking for a longer time for the preparation of the extract.

Investigations carried out by R. P. Wodehouse for me in 1915 showed in the case of ragweed pollen that there were present albumen and proteose, both capable of exciting skin reactions. The globulin present did not cause skin reaction in ten cases which were tested, and probably therefore need not be considered as an anaphylactic factor. The albumen is relatively unstable in solution, being readily affected by exposure to air, and is precipitated by boiling and treatment with alcohol in strength above $14 \%$. Freshly prepared pollen extracts given a skin reaction of a certain size, will, if exposed to air, after the lapse of a few weeks, even though prevented from decomposition by phenol, show a reaction of deeidedly smaller extent, and the preparation has at the same time become distinctly cloudy. Also freshly prepared pollen extracts show on boiling or treatment with alcohol an immediate clouding and a loss of their skin reactions of about one-half. The preparation, after this first diminution in its activity by coagulation of its albumen, will then show a skin reaction of the same degree of intensity for a much longer period, at least for several months. Since, therefore, we are dealing with a material containing an extremely unstable albumen, and a relatively stable proteose, our task is to obtain, if possible, a pollen extract which will retain a constant degree of activity for a sufficiently long period to enable us to make comparative observations from time to time in the same case. This may be accomplished either by placing the freshly prepared pollen extract treated with sufficient phenol or some similar antiseptic in tightly closed receptacles, and withdrawing, as occasion requires, the amount needed without exposure to air, or by placing definitely measured amounts of the pollen solution in small vials, and rapidly. evaporating to dryness, re-dissolving again when needed. Both of these methods are. already in use, and will, I believe, give good results. I have, however, for my own work, made use of the effect of alcohol on the albumen to effect its coagulation, and make my. own preparations as follows:

The pollen is obtained in the usual way as described by Wodehouse. One gram is soaked in a small amount of normal salt solution for forty-eight hours and filtered. The filtrate, which contains albumen, proteose and other proteids, is then treated with sufficient: alcohol to bring the alcohol content up to $20 \%$, by which albumen is thrown down in the form of flocculent precipitate. To this fluid is added enough $20 \%$ alcohol to make a volume of 500 C.C. In this, which is termed our standard extract, we have the amount of proteid extractable from one gram of pollen contained in 500 C.C. of $20 \%$ alcohol. Dilutions of this are made in the proportion of $1-2000,1-5000$, and $1-50,000$. Both in making these dilutions and in giving the injections; the bottle containing the material should be shaken sufficiently to distribute equally the suspended particles of albumen.

\section{ADMINISTRATION OF POLLEN EXTRACTS.}

The injections are started, if possible, sev. eral weeks before the expected attacks, although they have seemed of value even after the symptoms have begun. In the first instance we may speak of prophylactic treatment, in the second, of abortive treatment.

\section{PROPHYLACTIC TREATMENT.}

I advise patients to report, if possible, ten weeks before the expected onset of their attacks, although a shorter period is usually sufficient. The ordinary course of procedure is to inject from one to three minims of the 1-50,000 dilution. This causes in nearly all cases subcutaneous swelling ranging from one to three centimeters in transverse diameter, lasting from one to three days. This material as above made with coagulated albumen produces a different effect than does the injection of material of equal strength, where the albumen is in solution. In the first instance the local reaction is not immediately as marked, and requires a longer time. 
for its disappearance. Second, the coagulated material has not caused any of the general anaphylactic disturbances of which a few had been previously seen in using the dissolved albumen. After the reaction from the first injection has subsided, one may then double the amount, and a few days later give twice the amount of the second injection. The next higher strength of 1-5000 is taken, and three injections of this are given, ranging from three to seven or eight minims. Next a similar quantity in three doses is given of the 1 to 2000 , and finally the full strength of 1 to 500 , in doses ranging from 5 to 10 minims. The number of injections required during the first year has ranged from six to fifteen, depending upon the rapidity with which the dosage can be increased.

\section{ABORTIVE TREATMENT.}

If the individual reports at the beginning of his hay-fever, I-have adopted the method of giving small daily injections, without waiting for a subsidence of the reactions, the successive injections being made in the forearms and upper arms respectively. I do not believe that it has been demonstrated beyond dispute that in these cases there has been a pasitive arrest of the symptoms as a result of the injections, but nevertheless, so large a proportion of cases so treated have had the symptoms disappear in the course of a week, which would ordinarily have persisted for six weeks, that I am induced to continue this as the best means of affording relief.

At the close of the hay-fever season the patient may be assumed to have attained a relatively high degree of resistance to the pollen in question. With the omission of treatment the sensitization slowly and progressively returns, until at the beginning of the following year the skin tests show the same degree of intensity which they did originally. This fact is striking and has been brought out in all the cases under observation. An individual, for instance, who shows a No. 1 reaction, will, year after year, show one of the same degree, and a No. 4 reaction will, each spring, appear as a No. 4.

\section{RESULTS OF TREATMENT.}

Since the spring of $1914 \mathrm{I}$ have examined in private practice 330 cases of hay-fever. (The new cases appearing during the current year are not included, as they comprise, at the present date, June, a disproportionately large number of spring types.) In addition there were seen 18 cases of olfactory vasomotor rhinitis of a seasonal form.

Of the true anaphylactic type, 90 were from grasses, 237 from ragweed, 5 from maple, 4 from roses, 3 from oak, 1 from willow and 5 from birch. In these latter groups are reckoned only those patients whose symptoms were unmistakably and preëminently due to the plants in question. Cases, for instance, of grass hay-fever, giving also a moderate rose or oak reaction, are not included. A fairly large number, however (about $10 \%$ ), of the grass cases, showed definite ragweed reactions and symptoms.

Of the above 330 cases of true hay-fever 123 have received desensitizing treatment for two or more years. I have endeavored to classify the results according to the statements of the patients in connection with my own estimate of the situation, into four groups, as follows:

1. No improvement noted, 7 cases.

2. Improvement as compared with previous years, but showing, neverthelss, troublesome symptoms for a short time, 46 cases. These patients in general may be considered as only moderately well-satisfied with the results, and, in my opinion, were not materially better than most cases treated in previous years by cauterization and general hygienic measures.

3. Very definite improvement, apparently beyond criticism, was observed in 59 cases. These include patients with a previous history of severe attacks, who, under treatment, exhibited only slight symptoms, causing not more than noderate annoyance. Here are included patients with a previous history of hay asthma, who were able to go through two or more summers without asthmatic symptoms.

4. Five patients showed no hay-fever for two or more years. By this is meant complete $a b-$ sence of subjective or objective vasomotor disturbance, in spite of full exposure to pollen.

In examining further the results which have been accomplished we may consider first whether any difference has been observed in regard to the three types of hay-fever found, whether of the grass or ragweed or of the other scattered forms. No appreciable difference was observed between the grass and ragweed cases in this respect; but it should, however, be said that the early spring forms from maple and 
birch, which usually occur in association, while few in number, have been the least successful in overeoming the vasomotor symptoms. Whether this is due to some unrecognized pollen or not is uncertain, but a careful survey of the patient's neighborhood has failed to show any other trees or shrubs which might have been of influence. Dr. Key has reported from Texas severe hay: fever from the mountain cedar. I have not tested patients with the counterpart of the tree, namely, our common red juniper; but its distribution is limited, and it would seem unlikely that it could prove a factor. None of these cases has reacted to the pollen of pines which is so abundant at the season in question.

Another point to consider is the relative success achieved in the first two and the latter two years during which this form of treatment has been carried on. The essential difference in the mode of treatment in the last two years has been the use of larger doses with insoluble pollen. It has been observed that cases treated for three or four years have shown an improvement directly proportional to the amount of albumen employed in the preparation, and during the last season (1917) the proportion of cases who reported great improvement or complete immunity was larger than in the first two years, where an albumen in solution was employed. I prefer now to bring all cases up to a tolerance which enables them to receive a dose of five minims of the 1-500 solution.

\section{DISCUSSION.}

Dr. J. A. Turnbull, Allston: As to Bethlehem for a hay-fever resort it has improved some patients and on others it has had no effect, and still others it has made worse. The hay-fever cases should be tested out not only for the pollen but alsa for the foods and bacterial sensitizations. I have seen a number of cases in which the foods show marked reactions, but no objective or subjective disturbances during the other seasons. If the foods are taken at the time of the hay-fever season, with the inhalation of the pollen, which increases the amount of sensitive proteins, it is more than the patients can stand and their symptoms are made worse. I have found in a number of cases that at the time of the hay-fever, omitting those foods from the diet the patients were much better and easily desensitized, and their symptoms improved in every way.
As to the treatment of hay fever, I think a great deal depends on what media we use for the solvent for our proteins. $T$ have worked out a number of solvents and have found great differences in the reactions. I have been working with rlosse whish gave greatest reactions, and am waiting to see the results of aurumal sasss. Spring cusas showed gr'eat improvament. We often find rrainy cases coinmence in the cardy. spring and continue through to the early fali. I have seen some beginning with oak and birch and then are kept going by the grasses and the ragweed. Those cases continually load up first with one pollen and then with the others. They are extremely sensitive as to treatment. I have seen cases in which one or two doses of pollen protein have given a marked relief-even after one dose I have seen cases in which the symptoms were relieved at once. Other cases are more sensitive and take a greater number of doses. Occasionally we come across a person who does not react well to pollen. No doubt with the work which is being carried on, you will later on find something that is going to assist in those cases. Another thing is that with the pollen cases they often continue beyond the season. Those cases I have found are due either to some special food or to a bacterial protein. By omitting the food from the diet some cases are improved at once. In other cases where it is a bacterium I use the extract of the bacterium which has been used for the test; a solution made of this for desensitization, instead $0: 2$ the regular vaccine.

I have been greatly pleased with the papers that have been read this afternoon, and have enjoyed them very much.

Dr. W. H. SмIтH: I think anything that tends to bring asthma out of the murky darkness of a neurosis is of extreme value. We have tried to present to you up to date the work that is being done on hay-fever and asthma, and I have asked some of the men who are constantly seeing cases of asthma, and who saw cases before the vaccine and protein sensitization reactions were recognized, to speak about asthma and their experience with it before the fact was recognized and after-namely, in their experience are the asthma cases more clearly defined? Are the methods of treatment helping them to solve their problems in the asthma 